\title{
Exploration on Physics Experiment Teaching in Micro Video
}

\author{
Hengtong Ding \\ School of Physics \\ Tonghua Normal University \\ Tonghua,China
}

\author{
Li Zhang* \\ School of Physics \\ Tonghua Normal University \\ Tonghua, China \\ E-mail:*dbcy9999@163.com
}

\author{
Naiyuan Zhang \\ School of Physics \\ Tonghua Normal University \\ Tonghua, China
}

\begin{abstract}
In order to strengthen students' learning of physics experiments in middle schools and realize the perfect combination of modern information and physics teaching in middle schools, this paper is produced. Nowadays, as a new teaching method, micro-video teaching is more and more popular in daily physics experiment teaching, but there are some problems in the practical application process. Some teachers download some videos directly from the Internet as teaching resources to introduce new courses, but they ignore the fact that some content is too long and tortuous, so that the problem raised by the complex video content interfere the learning of students, which is problem we need to solve. We should scientifically evaluate alternative videos in line with scientific principles. By means of questionnaire, we find that most modern teachers have realized the importance of micro-video teaching. Therefore, we come to the conclusion that micro-video teaching will be paid more attention in the future, and will become more and more common in physics experiment teaching in middle schools, and will gradually become a kind of fixed teaching method.
\end{abstract}

Keywords-Micro video; Physics experiment; Teaching; Physics class

\section{THE APPLICATION FOUNDATION OF TEACHING} RESOURCES OF MICRO VIDEO IN PHYSICS TEACHING

\section{A. Concept and background of micro video}

Micro video is a new concept in recent years. At present, the media and academic circles also do not have an accurate concept. It is generally considered that short video is a kind of video content that is played on various new media platforms and suitable for watching in the mobile state and the short time leisure state, and the high frequency push video content, which ranges from a few seconds to a few minutes [1]. The content combines skills sharing, humor, fashion trends, social hot spots, street interviews, public education, advertising creativity [2], commercial customization and other topics. Because of the short content, you can separate into a film, can also become a series of columns. This paper refers to the video clips serving the physics teaching in middle schools [3]

At present, with the expansion of new media platform and diversification of content production [4], the integration process has also entered the deepening stage. Media forms infiltrate each other, incisively and vividly CTS fusion, communication model becomes three-dimensional. Short video is getting more and more attention [5]. Short video can be spread as a social platform that can bring you closer online and online. $\mathrm{Ne}$ space, increasingly vertical subdivision of the content of communication mode, no doubt by the Internet giant and various media attention.

\section{B. Characteristics of micro video teaching}

a) Short and difficult points are more prominent. Because of the short content, it is easier for people to concentrate on improving their learning efficiency and better knowledge construction.

b) There will be no communication process between teachers and classmates in the teaching. The teacher presents the content by simulating the electronic blackboard, and then explains it in the form of handwritten board. The whole process generates the video through the screen recording software.

c) In the course of teaching, the voice is clear and bright, and the speaking speed is moderate.

d) The presentation of video knowledge content is recorded on the basis of title. Many topics begin with examples, without any hints or bedding. 


\section{Micro video teaching theory}

Cognitive load is a multidimensional structure that represents the load added to the learner's cognitive system when dealing with specific tasks. This structure consists of three dimensions: the cause dimension which reflects the interaction between task and learner characteristics and the evaluation dimension of measurable concepts such as mental load mental effort and performance. The task characteristics are task form [6], task complexity, multimedia usage, time pressure and teaching steps. Relevant learner characteristics consist of professional knowledge level, age, and spatial ability. Psychological load is the aspect of cognitive load that originates from the interaction of task and subject characteristics. It is determined by our current knowledge of task and subject characteristics. The expected cognitive spatial demand index is regarded as a prior estimate of cognitive load. The intensity of effort paid by learners is an essential factor in obtaining reliable cognitive load estimates [7].

\section{THE INVESTIGATION AND ANALYSIS OF THE APPLICATION OF PHYSICS MICRO VIDEO TEACHING RESOURCES IN SCHOOL}

\section{A. Purpose of the investigation}

In order to better understand the teachers' application of micro-video in daily teaching, the questionnaire is carried out by secret ballot. The purpose of the investigation is: first, to understand the use of teachers' multimedia resources. Secondly, teachers who use multimedia resources and micro-video resources in classroom teaching are investigated.

\section{a)Content of the investigation}

The contents of teacher questionnaire are as follows: first, the basic information of the respondents. Second, the use of multimedia and video teaching resources in daily teaching.

\section{b) Implementation of investigations}

The questionnaire is in the form of electronic draft in Tonghua junior high school physics teachers. The student questionnaire is a paper questionnaire. 30 teachers were randomly selected by teacher questionnaire.

\section{B. Basic statistics}

The results of this survey (Fig.1,Fig.2) show that there are 20 male teachers and 10 female teachers. Among these teachers, there are 4 teachers with less than five years teaching age, 8 teachers with 5-10 years of teaching age, 16 teachers with 10-20 years teaching experience and 2 teachers with more than 20 years teaching experience. Of these, 10 are secondary teachers, accounting for 33 percent of the total, 19 of middle education level, 63 percent of the total, one of middle and senior education, accounting for 4 percent of the total, and young and middle-aged teachers account for the vast majority of the total.
The teachers' possession and configuration of computers are basically owned by both the office and the family, and the teaching and office hardware conditions have been realized. In the daily use of computers (Fig. 3), teachers can see that there are still more browsing of teaching courseware and video. $51 \%$ of teachers browse and download teaching resources in peacetime.

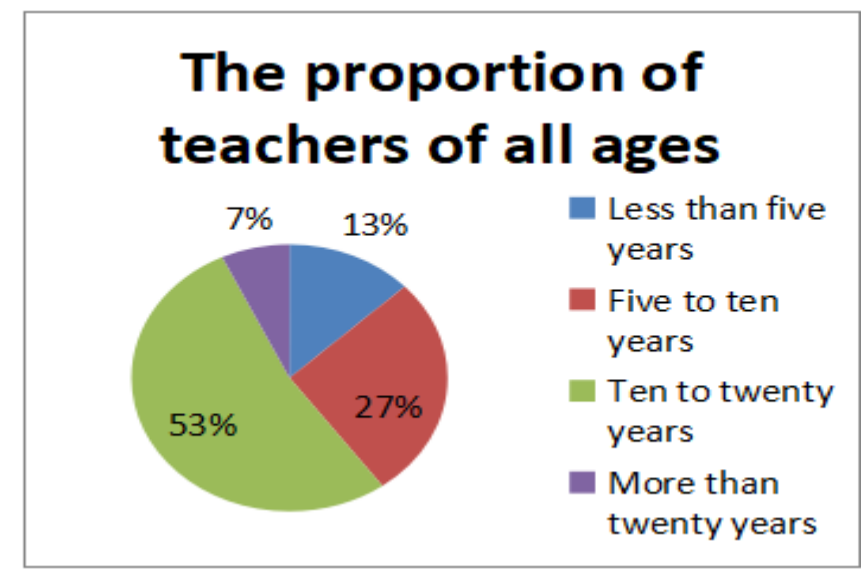

Fig. 1. The proportion of teachers of all ages

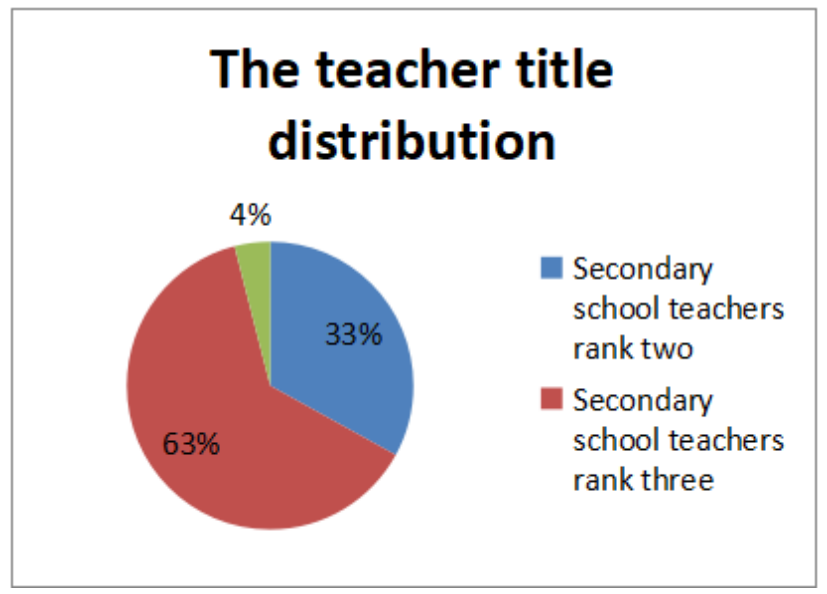

Fig. 2. The teacher title distribution

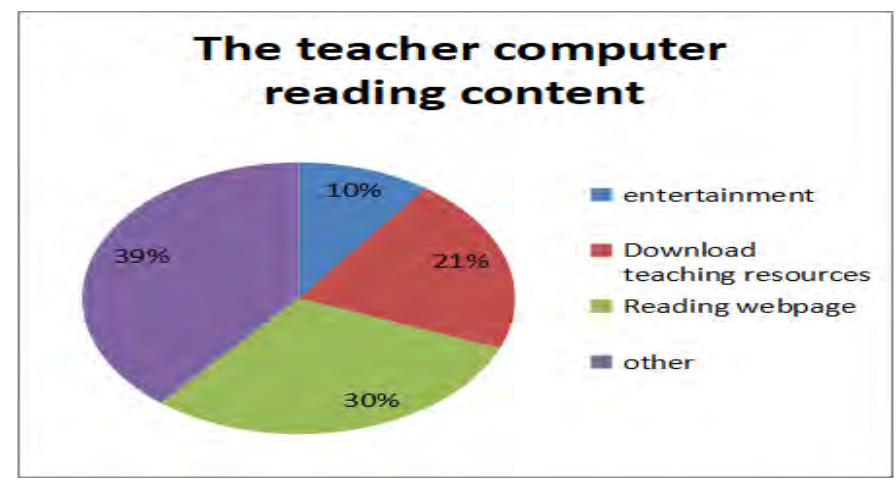

Fig. 3. The teacher title computer reading content 


\section{Status of the application of video teaching resources}

In order to understand the use of video resources in classroom teaching practice, the author investigates the frequency of the use of video resources, so as to provide some factual basis for the teaching and analysis of microvideo.

The frequency of using video resources in teachers' daily teaching is shown in Fig. 4. 66\% of the teachers who use multimedia resources for classroom teaching and $13 \%$ of the teachers frequently use them, which shows the importance of video resources in physics teaching in junior high school, but $21 \%$ of them use them occasionally.

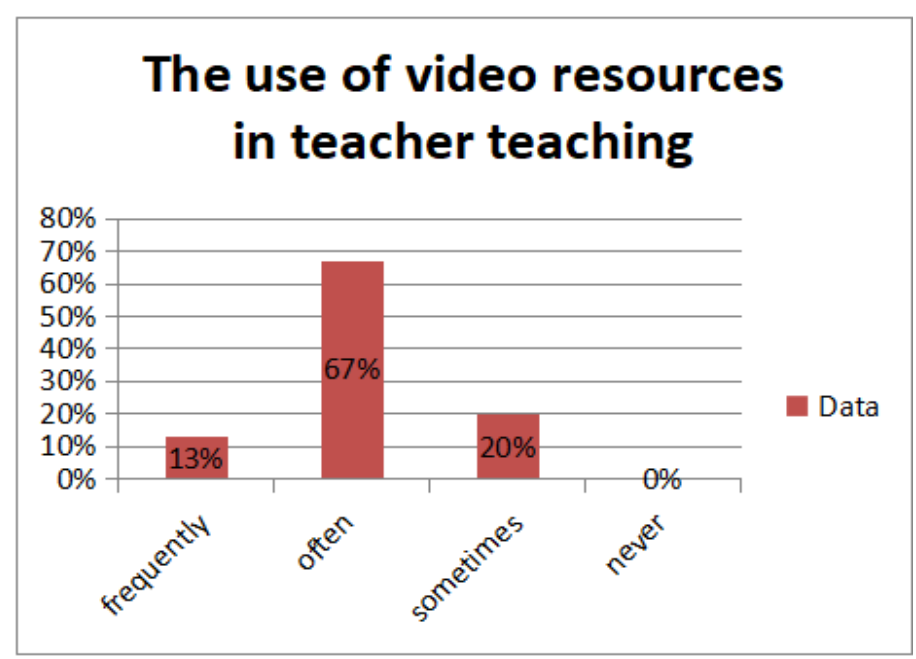

Fig. 4. The application of video resources in teacher teaching

In order to understand how long the video teaching is more beneficial to the students' understanding of physics problems and to the development of teachers' teaching, the author has carried out an investigation, as shown in figure 5. The results of the survey showed that 20 teachers were willing to use video resources within 5 minutes, and the proportion was the highest. It shows that most teachers prefer those short and flexible when choosing video teaching resources. Videos that are easier to combine with their own teaching. The survey also found that the vast majority of teachers believe that more than 5 minutes of video may have a greater impact on their dominant position, can be seen in less than 5 minutes of video can In order to meet the teaching needs, if the time is long, the students' attention may be divorced from the teaching content, but the negative effect will be produced.

\section{Findings}

Nowadays, most modern teachers realize the importance of micro-video teaching. Teachers generally think that video within five minutes is more beneficial to teaching, and can also give full play to students' subjective initiative and teachers' leading position. So as to improve the efficiency of the classroom. Teachers' understanding of video resources and the corresponding advantages of resources provide some guiding significance for the specific research of this paper.

\section{The length of video used}

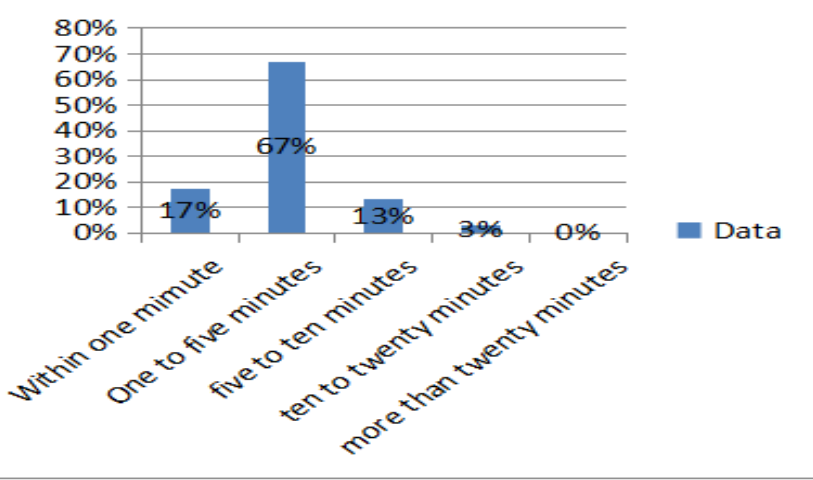

Fig. 5. The length of video used

\section{THE PROBLEMS IN THE APPLICATION OF MICRO VIDEO IN PHYSICS EXPERIMENT TEACHING}

With the rapid development of modern information technology, mobile Internet technology has provided important support for the development of micro-video. Nowadays, micro-video has been applied to daily physics experiment teaching more and more with the arrival of microlesson era. However, there will be some problems in the practical application process. Micro-video can fully stimulate the enthusiasm of students in teaching, but in practical teaching, there are often problems. For example, in the creation of situations, many teachers often choose pictures or animated videos as the introduction of experience situations. Some teachers download videos directly from the Internet to enrich the teaching content as a teaching resource for introducing new courses, while others download videos directly from the Internet as a teaching resource for the introduction of new courses. The content is too long and procrastination, causing questions to be raised by complex video content, students' attention is scattered seriously, and some students even ask questions today.

The contents of the study are far from each other. For free fall, there are plenty of videos to choose from and a lot to live in. The entertainment teacher chose the video of bungee jumping (shown in Fig. 6), originally out of good intentions to expand the knowledge of students, but the vast majority of students feel unable to understand, watching the video when the amount of information. The key to this video is whether or not the speed of the person changes in the course of the student's observation of the person's whereabouts, and the basis for this change is the focus of this lesson. But because of this new thing, it will have a great influence on the students' observation. Their attention is often drawn by the characters in it. Before broadcasting the video, the teacher asked the question, "watching the video and pointing out what you have observed?" some students actually answered, "will people be afraid?" Such an answer, far from what is studied in the classroom, also reduces the effectiveness of learning. This kind of thing makes us see that the video has chosen a way to 
teach in a very precise way, not to take advantage of the doctrine, no more personal modifications, and this has led to some outdated, cumbersome videos that have greatly reduced the interest of students. Sometimes it even backfires. Let students do not like to study, lose interest.

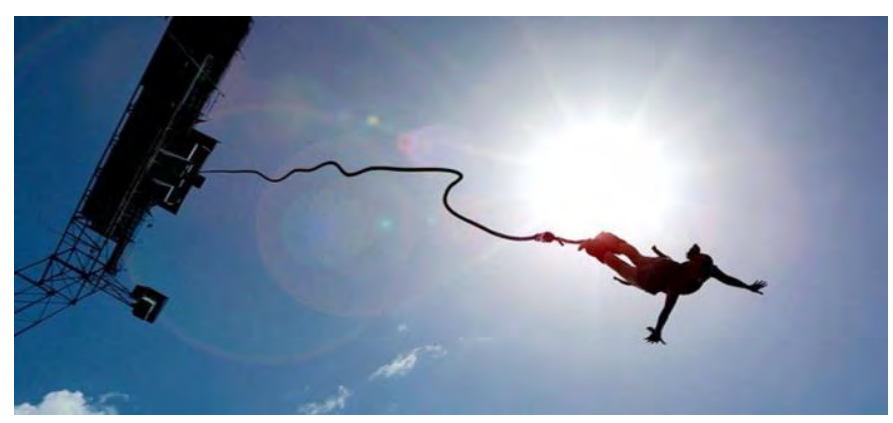

Fig. 6. The entertainment teacher chose the video of bungee jumping

\section{THE METHOD TO SOLVE THE PROBLEMS IN MICRO RESOURCES USED IN PHYSICS EXPERIMENT CLASSROOM TEACHING}

The methods and approaches of micro video resources used in physics experiment teaching should be more devoted to teaching design before class and scientific principles should run through teaching design classroom teaching and learning after class. Whether it is prepared before class or used in the classroom micro video, should be carefully identified, not scientific errors. The micro video used for students' learning after class should be checked scientifically as an alternative video.

In addition, if appropriate, the introduction of micro-video can arouse students' interest and enthusiasm by integrating the elements of life into the teaching of the new course. For classes with active atmosphere, combined with some micro videos with more explanation and more traditional content, the impetuous psychology of students when watching micro videos is eliminated; For classes with a lower classroom atmosphere, micro videos with less explanation and novel picture content are used. Arouse students' enthusiasm to participate in physics class.

\section{CONCLUSION}

Since the middle of 1980's, each junior high school has set up the "junior middle school experiment center" of physics laboratory and biochemistry laboratory model one after another. However, this is only a general situation in the current junior high school experimental equipment. Throughout the rural and urban sectors, we have to admit that there are corresponding problems in the teaching resources of physics experiments. When I was in high school, Our school experiment teaching because of the insufficient investment, did not purchase the corresponding experimental equipment and equipment. When doing experiments, there is no open physics laboratory, and no physical laboratory instrument, which can only be shown to students by drawing on the blackboard or explaining directly according to a book. In 2002, the experiments stipulated in the syllabus could not be carried out normally, so that the students' ability to do the experiments was poor as a whole. To some extent, teachers only pay attention to the explanation of basic knowledge and the cultivation of students' ability to solve problems, but neglect the cultivation of students' experimental ability. Students are only mechanical imitation, lack of hands-on and mental opportunities, the ability can not be improved accordingly. The role of micro video is to pay attention to this process, create a kind of life and physics fusion scene, not only "a group of stimuli", but also with the teaching objectives. A human-optimized scene that combines cognitive activities with situational activities. This kind of conscious creation, excellence, Under the inspiration of the teacher's language, the students are placed in a specific psychological field, which not only engrossed in the students' students, but also stimulated the students to participate in the study actively and emotionally. Thus, the students initiate active and conscious learning activities.

The author hopes that in the future teaching career, we can explore and develop more and better experimental resources of physics micro video, and find out its greater use in physics teaching in middle school. At the same time, it is hoped that more and more experts and scholars and teachers can study this problem and provide more valuable teaching resources for physics teaching in middle schools.

\section{ACKNOWLEDGMENT}

This research was financially supported by Research Foundation of Education Bureau of Jilin Province (Grant No.2016238 and Grant No.JJKH20180860KJ) and by the Project of Education Department of Jilin Province College students venture project (year 2018).

\section{REFERENCES}

[1] Chen Gang, Physics teaching design, Shanghai: East China normal University Press, 2009.

[2] Feng Jie, Theory of Physics Curriculum and Teaching in Middle School, Beijing: Peking University Press, 2011, pp. 1887-1888.

[3] Pan Yujin, Statistics of Education and Psychology, Zhejiang University Press, 2006, pp. 72-76.

[4] Edgar Dale, Audio-Visual Methods In Teaching, New York: Holt, Rinehortand Winston, 1969.

[5] Sweller J. Implications of Cognitive Load Theory for Multimedia Learning. In Mayer RE. (Ed.).The Cambridge Handbook of Multimedia Learning, New York: Cambridge University Press, 2005, pp. 19-30.

[6] Lin Ping, On the cultivation of Information Literacy of Physics normal School students, Physics, Hunan Middle School, 2013 (4).

[7] Chen Ling, Wang Xiaofeng, Application of Microvideo in Teaching and Research, China Education Network, 2013 (9). 